\title{
HIP HOP ET MOUVEMENTS SOCIAUX : L'ÉTAYAGE DES LUTTES SOCIALES ET POLITIQUES PAR LES RAPPEURS
}

Deux exemples en France et au Burkina Faso

Alice Aterianus-Owanga et Marie Sonnette

\section{La Découverte | « Mouvements »}

2018/4 $n^{\circ} 96 \mid$ pages 54 à 55

ISSN 1291-6412

ISBN 9782348040870

Article disponible en ligne à l'adresse :

https://www.cairn.info/revue-mouvements-2018-4-page-54.htm

Distribution électronique Cairn.info pour La Découverte.

(C) La Découverte. Tous droits réservés pour tous pays.

La reproduction ou représentation de cet article, notamment par photocopie, n'est autorisée que dans les limites des conditions générales d'utilisation du site ou, le cas échéant, des conditions générales de la licence souscrite par votre établissement. Toute autre reproduction ou représentation, en tout ou partie, sous quelque forme et de quelque manière que ce soit, est interdite sauf accord préalable et écrit de l'éditeur, en dehors des cas prévus par la législation en vigueur en France. Il est précisé que son stockage dans une base de données est également interdit. 


\section{Hip hop et mouvements sociaux : l'étayage des luttes sociales et politiques par les rappeurs Deux exemples en France et au Burkina Faso}

\begin{tabular}{l} 
PAR ALICE \\
ATERIANUS- \\
OwANGA* ET \\
MARIE SoN NETTE** \\
\\
\hline 1. Voir les actes en \\
ligne du colloque à \\
l'adresse suivante : \\
https://colloquehh. \\
hypotheses.org/ \\
2. Assassin est un \\
groupe de rap fondé en \\
1985 par les rappeurs \\
Rockin'Squat et Solo. \\
Figure importante \\
de la scène dite \\
"indépendante " et \\
"consciente " en France \\
dans les années 1990, \\
trois de ses albums sont \\
certifiés disques d'or en \\
1992, 1995 et 2000. \\
3. Le sociologue \\
sénégalais Abdoulaye \\
Niang participait \\
également à la table \\
ronde initiale, et il avait \\
discuté des liens entre \\
rap et mobilisation \\
politiques en décrivant \\
le cas du mouvement \\
Y'en a Marre au \\
Sénégal. \\
* Anthroporatoire \\
Assistante à l'Université \\
de Lausanne. \\
**aittresse de confé- \\
\end{tabular}

$\longrightarrow$ es deux entretiens ont été réalisés après une table ronde qui s'est tenue en février 2017 à la Maison des métallos à Paris dans le cadre du colloque "Conçues pour durer: Perspectives francophones sur les musiques Hip hop "1. En menant une discussion avec Madj, ancien manager du groupe de rap français Assassin ${ }^{2}$, et Smockey, rappeur burkinabè ${ }^{3}$, nous souhaitions comprendre comment les artistes Hip hop peuvent constituer des leviers de mobilisation importants pour les mouvements sociaux et politiques, ce à partir de plusieurs terrains internationaux.

Les musiques Hip hop ne sont pas politiques par essence. Elles s'organisent au sein de scènes musicales extrêmement vastes et diverses et ne poursuivent pas un but commun et unifié. Alors qu'une partie des artistes Hip hop s'attachent à adopter une posture distante et éloignée de tout engagement politique, quelques-un·e.s mettent en musique une parole politique et d'autres encore choisissent d'intervenir plus directement au sein de mobilisations ou de mouvements sociaux. Comme beaucoup d'autres avant eux·elles, ces artistes interviennent donc en politique avec des ressources spécifiques liées à leur notoriété ou leurs compétences artistiques. Ils et elles se font tantôt les moteurs des mobilisations, comme les actrices et acteurs du mouvement Y'en a Marre au Sénégal ou du Balai citoyen au Burkina Faso, tantôt leur relais public et médiatique, comme l'illustrent en France les concerts de la Marche de la dignité ou les vidéo-clips du Collectif contre le contrôle au faciès.

Smockey est un rappeur burkinabè, co-fondateur du mouvement Balai citoyen, qui a joué un rôle déterminant dans la chute de l'ancien président Blaise Compaoré en 2014. Madj est producteur, fondateur du label Assassin productions et ancien manager du groupe Assassin. Il a été la cheville ouvrière de nombreux projets musicaux politiques dans les 
années 1990 et 2000, notamment la production du morceau 11'30 contre les lois racistes pour le Mouvement de l'immigration et des banlieue en 1997. Ces deux entretiens illustrent les dynamiques d'intersection entre rap et politique qui ont fait date dans l'histoire politique des deux pays, bien qu'à des échelles différentes. Ils forment aussi bien une mémoire de l'intervention des artistes en politique que du mouvement révolutionnaire au Burkina Faso et de l'histoire politique des quartiers populaires et de l'immigration postcoloniale en France.

Enfin, ils abordent toute la complexité de la rencontre de deux mondes sociaux constitués : le monde de la musique professionnelle d'un côté et le monde militant de l'autre. Les normes de fonctionnement de l'un peuvent parfois être incomprises par l'autre. Dans les deux cas présentés ici, si la rencontre fonctionne, c'est parce que des artistes mettent au service des mouvements la connaissance qu'ils et elles ont de leur scène musicale. Cependant, ces postures d'engagement actif restent exceptionnelles dans les mondes du rap au sein desquels ils et elles évoluent. Elles sont liées à leurs trajectoires individuelles singulières : l'engagement politique de Madj et de Smockey précède leur carrière culturelle et artistique. Ni exemplaires ni représentatives des scènes artistiques au sein desquelles ils évoluent, les parcours de ces artistes confirment en creux l'absence d'une essence politique du rap, mais éclairent surtout les enjeux, les moyens et les conditions de l'action poli-

\section{Ni exemplaires ni représentatives des scènes artistiques au sein desquelles ils évoluent, les parcours de ces artistes confirment en creux l'absence d'une essence politique du rap.} tique d'artistes dans des mouvements sociaux. Entre héritages familiaux, parcours militants, rencontres avec des mouvements associatifs et événements historiques, les actions de Smockey et de Maître Madj mettent en lumière les mécanismes qui conduisent certain'e's artistes à transformer leur outil d'expression artistique en un instrument d'action politique. 